\title{
ON THE RELEVANCE AND NATURE OF REGIONAL INFLATION DIFFERENTIALS: THE CASE OF SPAIN
}

Enrique Alberola \& José Manuel Marqués

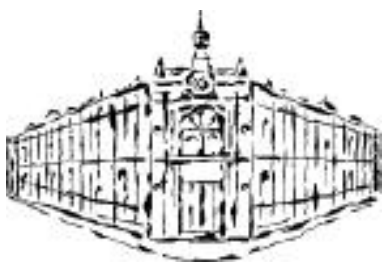

Banco de España - Servicio de Estudios

Documento de Trabajo n. ${ }^{\circ} 9913$ 
ON THE RELEVANCE AND NATURE OF REGIONAL INFLATION DIFFERENTIALS: THE CASE OF SPAIN

\author{
Enrique Alberola \& José Manuel Marqués
}




\begin{abstract}
This paper studies two aspects of the behaviour of provincial relative prices in Spain: the relevance and the nature of provincial inflation divergences and relative price shifts. Inflation differentials are found to be small (the range is less than half point per year in the long-run), but deviations of relative prices from equilibrium can be very persistent. Relative price shifts turn out to be determined by characteristics which are intrinsic to very deep economic integration, in particular, price and wage mechanisms which operate at the national level. This is in stark contrast to evidence on the determinants of real exchange rates among countries; as a consequence, the Balassa-Samuelson hypothesis results clearly rejected. Therefore, while admiting that inflation differentials among EMU participants are possible, their nature will be different from those existing among Spanish provinces.
\end{abstract}




\section{1.-INTRODUCTION}

Apparently, this is a paper on a non-issue. Does anyone really care about inflation differentials among regions or provinces in a country with a common currency ?. Surely, not the national central bank since management of monetary policy is directed to monitor national inflation. Hardly do citizens or local governments. Provincial inflation rates hardly make a headline on the press.

Notwithstanding this, there is a renewed interest on the question of inflation differentials within a common currency as the process European Monetary Union (EMU) gathers pace. A monetary union implies a single monetary policy and the abolition of exchange rates within the area; according to a well-established monetary view of the inflation process, it should also mean a common inflation rate. Moreover, the prospect of EMU has brought about a fast convergence in inflation rates among candidate countries.

In contrast to this, a branch of the literature has pointed out that there may be real factors (supply and demand shocks, transportation costs, segmentation of markets or non tradability of certain goods) that make possible substantial shifts in relative prices, conveyed in enduring inflation differentials between regions. Empirical evidence at the regional level is scant, but the literature on real exchange rates movements (v.g. relative price shifts) between countries with different currencies shows that the shifts are large and permanent, implying, contrary to conventional wisdom, that real factors play a role in the evolution of prices.

It is important to stress here that eventual inflation differentials in EMU would not affect the area-wide monetary policy stance, since the European Central Bank will also only care about price stability at the Union level. Hovewer, national inflation rates will be relevant for national countries in assessing the competitiveness of the economy, and they might be a cause of major concern if, for a particular country, domestic inflation differentials with EMU are positive.

The relevant question is whether homogeneous inflation rates can be taken for granted. Studying regional price evolutions in a country with a common currency is important because it may shed some light on the possible existence and characteristics of inflation differentials in 
a common currency.

This is the aim of this study on the evolution of prices in Spanish provinces during the period 1960-1998. The analysis makes use of descriptive statistics and panel cointegration techniques, and it shows that relative shifts in provincial prices are very persistent, if not permanent, leading to long-lasting inflation differentials which are however small on a year by year basis.

At this point, we could have extrapolated this result to EMU and infer that inflation differentials will persist in EMU but that they will be too small to care about. But this conclusion is misguiding because there is a qualitative but substantial difference between EMU and the existing monetary unions in Europe, v.g.: the latter are nation-states.

European countries are characterised by deep economic and political integration, which, respectively, reduce the scope and the perceived importance of inflation differentials. Political integration implies that the real economic entity is the nation, and notions as competitiveness, external deficits and so on refer to the nation. Hardly anyone cares about regional competitiveness or the regional current account, but -as suggested above- countries will worry about their "regional" competitiveness in EMU.

Most important in our context is the role of economic integration. Even with free trade or a Single Market, markets are much more deeply integrated within countries that they will be in EMU, at least for the foreseeable future.

On the one hand, labour and product markets are more integrated at the national level. The existence of national markets is based on tradition, history and the existence of a common tax system, regulation, legislation etc. The Single Market and, now the EMU imply an important push towards more integration, but this will be a long process. Therefore, the nature of relative price shifts or inflation differentials between regions in a country may differ from that in countries within EMU, and therefore it may be inadequate to extrapolate regional inflation differentials to EMU.

The second part of the paper explores the relation between economic integration and the characteristics of provincial relative prices. The results of the panel estimation indicate that the theories that explain shifts in the real exchange rate among different currencies do not operate among the Spanish provinces, suggesting that national factors -in particular the price and 
wage mechanism operating at the national level- make the difference.

All in all, the conclusion of this paper is that inflation differentials should not be ruled out in a monetary union, but that their nature will be different -at least in the medium run- from current regional inflation differentials, because current monetary unions are intrinsically different from the future EMU.

The paper is organised in two parts. The first part deals with the analysis of relative prices at the provincial level and it is divided into three sections. In the next section, we present the concept of PPP, which is the theoretical framework to analyse provincial prices; in section three, the features of provincial inflation are described and in section four we explore the mean reversion properties of provincial prices, that is, whether deviations from PPP are transitory or permanent, both in a univariate and a panel context. The second part deals with the sources and nature of relative prices. In section five, the theoretical models to explain provincial divergences in inflation are briefly presented and in section six, we test the theoretical hypothesis. Section seven concludes.

\section{2.-RELATIVE PRICES. THEORY AND EVIDENCE}

This paper is closely related to studies on the law of one price and purchasing power parity (PPP). The law of one price establishes that the price of goods should equalise between economic areas. For the good $j$ this implies that the ratio of relative prices $P_{R E L j}$ is equal to one:

$$
P_{R E L j}=P_{1}^{j} / P_{2}^{j}=1
$$

where the subscripts 1 and 2 refer to countries or regions ${ }^{(1)}$. The law of one price usually fails to hold, as documented by Isard (1977) or Giovannini (1988). The existence of tariffs, nominal exchange rates (between countries) or transportation costs sets a wedge between the price of the same products in different areas. However, more recent evidence has studied the law of one price within countries (i.e. within a monetary union), thus eliminating the effects of tariffs and nominal exchange rates (Engel \& Rogers (1996), Parsley and Wei (1996)), and deviations from the law of one price persist.

\footnotetext{
${ }^{(1)}$-The law of one price is typically defined for economic areas with different currencies. In this case, the price level for country 2 , the 'foreign' country is specified in terms of the domestic currency $P_{2}=E P_{1}$, where $E$ is the nominal exchange rate.
} 
The Purchasing Power Parity (PPP) theory generalises the law of one price to a basket of goods, $P_{R E L}=P_{1} / P_{2}$, where the general price indices are weighted averages of the national basket of goods. For further convenience it is preferable to specify the PPP in logarithmic terms:

$$
P P P: p_{R E L}=p_{1}-p_{2}=0
$$

where low case letter refer to the $\log$ of the variables v.g. $p_{R E L}=\log \left(P_{R E L}\right)$. This equation is referred to as the absolute PPP (allowing in general a constant instead of a zero in estimation). A less stringent specification, known as relative PPP considers the same equation in differences:

$$
\text { relative PPP: ? } p_{R E L}=? p_{1^{-}} ? p_{2}=0
$$

implying that, with a common currency, inflation differentials are null.

The PPP theory should be considered as a long-run relationship. Therefore, the most standard PPP tests consists on testing for the stationarity properties of the relative price series. Relative prices are in general non-stationary, implying the rejection of PPP. However, recently the PPP theory has regained relevance, thanks to the use of longer data series and panel data techniques ${ }^{(2)}$. Although both avenues tend to accept the PPP, they are not free of problems. In particular, the panel cointegration techniques, which we will also use in this paper, tend to accept the PPP for the whole panel when it holds for any of the individuals. In any case, although PPP might be accepted to hold, the deviations from mean reversion are large and persistent, not only for different countries but also for regions within countries as Parsley and Wei (1996) and Cecchetti et al. (1998) show for the U.S.. Consensus view considers that the average life of deviations is around four years.

\section{3. -ANALYSIS OF PROVINCIAL INFLATION}

In this section we describe the features of inflation differentials between provinces. The data used have been provided by the INE and refer to the consumer price level

(2) - See McDonald (1998) and Rogoff (1996) for recent surveys on this literature and Rogoff \& Obstfeld (1995) for a reappraisal. 
(CPI) indices for the fifty Spanish provinces ${ }^{3}$. The frequency is quarterly and the period covered is from 1961 to 1998 (first quarter).

In the text, aggregate results are presented, but in appendix 1, a more detailed provincial analysis can be found. Two subsamples are also considered (1961:1-1976:4 and 1977:11998:1). Our interest is to capture differentials abstracting from the cycle influence. The simplest way to do this is to compute differentials for periods longer than a business cycle.

In figure 1, we have first computed as a dotted line the (centered) moving average of national inflation over ten years. The solid line represents the spread in inflation between the three highest and three lowest inflation provinces at each point of the ten-year moving average ${ }^{4}$. We can observe a smooth downward trend in the spread from $2.5 \%$ to around $1.2 \%$. The higher levels of national inflation in the late seventies are not reflected in larger spreads, but the final reduction in the spread coincides with the process of inflation stabilization at the national level. Figure 2 complements this analysis with two dispersion measures for the same moving averages. The dotted line is the standard deviation of the moving averages, which displays a path similar to the spread. The solid line is the variation coefficient (i.e. the ratio of the standard deviation over the mean), which shows that the reduction in the spread in the last years has been proportionally lower than the reduction in inflation. This suggests that, even in a context of stable prices, interprovincial inflation differentials may persist ${ }^{5}$.

This brief descriptive analysis has shown that inflation differentials are relevant at the provincial level even for low levels of inflation, although their size is relatively small. However, these conclusions tell us little about the duration of relative price shifts between provinces and the persistence of inflation differentials, which is the actual topic of our study. We have just considered time periods of ten years, but it may be possible that high inflationary provinces in one period become low inflationary provinces in the next, therefore reverting to

\footnotetext{
3 -The data refer to province capitals until 1992 and there are four bases linked (1961,76, 83 and 92)

${ }^{4}$-In this way, we decrease the potential distortion of outliers

${ }^{5}$-An alternative possible explanation of differentials is the different composition of consumption baskets among provinces (the so-called composition effect). We made same corrected measures and the effect was negligible.
} 
the initial relative price level. Thus, the next step is to analyse the mean-reverting properties of relative prices.

\section{4. -MEAN REVERSION IN RELATIVE PRICES}

PPP implies that relative prices are stationary. In this section, we will test for the stationarity of provincial relative prices and the persistence of their deviations from their equilibrium value is estimated.

The series of provincial prices are defined as an index with initial value equal to 1 $\left(P_{i 0}=1\right)$ In order to carry out the analysis it is necessary to define a numeraire $\left(P_{t}\right)$ to which all the series are referred to. We could take any province as numeraire and the obvious option is Madrid, capital of Spain and located in the centre of the country. However, the fact that it is one of the lowest inflation provinces, make us dismiss this option and we take the national rate as numeraire ${ }^{(6)}$. Relative price series are defined in logs, as $p_{R E L i t}=\log \left(P_{i} / P_{t}\right)$, so that the initial value equals zero and the deviations from zero can be read in percentage points.

Figure 3.a displays the relative prices for the two most and two least inflationary provinces in the sample. Note that accumulated inflation differentials have reached around $+20 \%$ for Vizcaya (around half a point differential per year on average-see table in the appendix) and $-15 \%$ for Caceres and Zamora (-.3\% per year). These magnitudes are not dramatic but they are relevant. We have also plotted in figure 3.b some cases of meanreversion, where we can see that deviations are in any case large and persistent.

\section{1.-Testing for mean reversion province by province}

Stationarity of relative prices can be analysed more formally by testing for the integrability of each provincial relative price. A series is said to be stationary or integrated of order zero $(I(O))$ when it is shown to revert to a constant mean; otherwise, when the series displays a stochastic trend or unit root is said to be integrated of order one $(I(1))$ and shows no mean reversion. The Dickey-Fuller tests for unit roots, which are now of standard use, are

(6)-Other alternatives could be possible. We could have taken the province in the median of the distribution or we could have compute the (unweighted) national average. The national price level is quite similar to this alternatives and therefore we have opted for it. 
obtained by running the following regression province by province:

$$
? p_{R E L i t}=a_{i}+\beta_{i} p_{R E L i t-1}+\sum_{j=1}^{k i+1} ?_{i j} p_{R E L i t-j}+u_{i t}
$$

Where $i$ refers to province and it is easily shown that $\beta_{i}=1-?_{i}$ and $?_{i}=\sum ?_{i j-1}$, that is, $?_{i}$ is the parameter associated to the autorregresive process of order $k i$ of the provincial series of relative prices. A value of $?_{i}$ close or equal to one implies the existence of a unit root in the data. Thus, the null hypothesis of unit root is specified as $H_{0}: \beta_{i}=0 \quad\left(?_{i}=1\right)$ against the alternative that $\beta_{i}>0\left(?_{i}<1\right)$. The number of lags $(k i)$ is determined province by province, according to the significance of the lags. As we have said above, testing for the stationarity of relative prices is equivalent to testing for the PPP. Note that the possibility of a deterministic trend in the data is not contemplated, since the PPP hypothesis implies a constant mean.

The table in appendix 1 presents the order of integrability for each province and table 1 below displays an aggregate summary. We can observe that, for the full sample, at the $10 \%$ level the hypothesis of a unit root is accepted for 41 the provinces (82\%). The sub-sample analysis shows that in the more recent period the series display a unit root in more cases (86\% against 70\%). The last columns show the cases in which a province shifts from stationary to non-stationary, or viceversa, from sample to sample. This gives us a hint of structural stability of the processes, since only $30 \%$ of the provinces change its stochastic behaviour at the $5 \%$ level.

\begin{tabular}{|c|c|c|c|c|c|c|}
\hline \multirow[t]{2}{*}{$T A B L E 1$} & \multicolumn{6}{|c|}{$\begin{array}{l}\text { INTEGRATION UNIVARIATE TEST } \\
\text { VARIABLE:LOG CPI PROVINCIAL -LOG CPI NATIONAL }\end{array}$} \\
\hline & $\begin{array}{r}\text { ORDER OF } \\
\text { I( }\end{array}$ & NTEGRATIC & $<$ Years & $>2-4$ Year & ERSISTEN & $>0$ Yoars \\
\hline FULL SAMPLE & $41(82 \%)$ & $43(86 \%)$ & $8(16 \%)$ & $13(26 \%)$ & $14(28 \%)$ & $15(30 \%)$ \\
\hline $1961-76$ & $35(70 \%)$ & $39(78 \%)$ & $22(44 \%)$ & $14(28 \%)$ & $5(10 \%)$ & $9(18 \%)$ \\
\hline $1977-98$ & $43(86 \%)$ & $47(94 \%)$ & $11(22 \%)$ & $7(14 \%)$ & $9(18 \%)$ & $23(46 \%)$ \\
\hline CHANGE & $32(44 \%)$ & $14(28 \%)$ & - & - & - & - \\
\hline
\end{tabular}

The unit root tests show that most of the series are not stationary, that is, from an econometric standpoint, deviations from equilibrium are considered as permanent. Unit root tests just differentiate transitory from permanent deviations but we are also interested in the duration and persistence of these deviations.

One standard measure of this duration is the half-life of deviations produced by a shock 
to the series, defined as the time that it takes to reverse half of the shock to a series. Since ? ${ }_{i}$ is the sum of parameters of the $\mathrm{AR}\left(\mathrm{k}_{\mathrm{i}}\right)$ process for each series, the half-life of deviations can be computed as $\ln (2) / \ln \left(?_{i}\right)$. The estimates of $?_{i}$ are known to be downward biased, but this bias can be corrected adding to them $\left(1+3 ?_{i}\right) / T$, where $T$ is the sample size, as Kendall (1954) suggests. The last columns in the table report the provinces for each case according to the duration of the deviations. Note that they are extremely long-lasting in most of cases. Actually, for 29 provinces the half-life of deviations is more than four years which is the consensus estimate of deviations from PPP between countries. It is also remarkable that in the second sub-sample adjustment tends to be even more sluggish, with 31 the provinces showing half-life deviations of more than ten years against only fourteen in the first sub-sample.

\section{2.-Testing for overall mean reversion}

The previous analysis has two drawbacks. The first is of econometric nature. Campbell and Perron (1991) showed that unit root tests tend to accept the unit root when the process is actually stationary, v.g., they have low power to reject the null. Therefore, the unit roots results would overestimate the importance of permanent deviations in relative prices. The second drawback has to do with the presentation of the results. At this point, it is not possible to state, in the aggregate, the non-stationarity of relative prices or the average-life of deviations, since the analysis is province by province.

Panel data analysis allows overcoming some of these problems. As we mentioned above, panel techniques have recently been devised to test the integrability of a panel of series. These tests have the main advantage of increasing the sample size by pooling data, but they also have problems. They were primarily devised to overcome the tendency of univarite unit root tests to reject stationarity. They do it indeed but they are constructed on the basis that all the series in the panel are stationary. Taylor and Sarno (1998). actually show that the unit root hypothesis may be rejected if just one of the series is stationary. Therefore, panel unit roots tests tend to overestimate stationarity. Despite this caveat, we will perform two of these tests, the Levin and Lin (1993)-denoted by LL, and the Im, Pesaran and Shin (1997) -denoted by IPS- tests. There are two main reasons: on the one hand, if the unit root hypothesis is not rejected, non-stationarity of real exchange rates at the provincial level will become a very robust result; on the other hand, the Levin and Lin tests provides an overall value for the halflife of deviations.

Both tests are based on the multivariate version of the ADF tests, which consists in the following panel regression: 


$$
? p_{R E L i t}=a_{i}+\beta_{i} p_{R E L i t-1}+\sum_{j=1}^{k i+1} ?_{i j} p_{R E L i t-j}+u_{i t}
$$

where $a_{i}$ refer to individual effects. The tests differ in the treatment of $\beta_{i}$. The LL test restricts all the $\beta_{i}$ to be equal to a single $\beta$ and test a unit root against the alternative that $\beta_{\neq 0}$, while the IPS test allows divergence among the provincial parameters and test the unit root against the alternative that some $\beta_{i \neq}$. The IPS test is thus less restrictive and has in fact more power, but the LL has the advantage to provide a estimate of ? for the whole panel, which is useful to compute the half-life of deviations.

The IPS test consists of comparing the previous equation (unrestricted model), estimated province by province, with a restricted model where all the $\beta_{i}$ s are assumed to be zero. The (mean) likelihood ratio statistic $(L R)$ provides the test for the unit root and they suggest complementing this test with the average t-student $\left(t_{\text {avg }}\right)$. The distributions of these statistics are not standard and they provide the tables in their paper. The LL test makes use of actual panel regression to estimate $\beta$ and ?, but only after allowing for different degrees of autocorrelation in each province. The result is an adjusted t-statistic $\left(t^{*}\right)$, which is distributed as a normal ${ }^{(7)}$.

\begin{tabular}{|c|c|c|c|c|}
\hline TABLE 2 & \multicolumn{2}{c|}{ PANEL TEST } \\
& VARIABLE:LOG CPI PROVINCIAL-LOG CPI NATIONAL \\
& \multicolumn{2}{c|}{ IMS TEST } \\
& LR & $t_{\text {Avg }}$ & $t^{*}$ & Half Life \\
\hline & & & & \\
FULL SAMPLE & $3.37 * *$ & $-2.02^{*}$ & $-14.92^{*}$ & 4.52 \\
$1961-1976$ & $4.91 *$ & $-2.14^{*}$ & $-14.58^{*}$ & 1.55 \\
$1977-1998$ & 2.55 & -1.66 & $-11.33 *$ & 5.45 \\
& & & & \\
\hline
\end{tabular}

The asterisk means rejections of unit root at the $1 \%$ level( $\left.{ }^{*}\right), 5 \%$ level $\left({ }^{* *}\right)$

Table 2 presents the results of the tests. For the full sample and the first sub-sample (1961-79) both tests reject the unit root, but for the second subsample (1980-98) the IPS test accepts the unit root hypothesis. Indeed, the IPS test show in the other two cases values for the statistics very close to the acceptance region and in fact for the whole sample the unit root hypothesis could not be rejected at the $1 \%$ level. The half-life of deviations is very similar to the consensus value at the international level (around four years), but we observe, as in the

(7) - The appendix 2 extends on the implementation of these tests. 
previous cases, that for the second sub-sample the half-life is quite larger than in the first subsample (five and a half versus one and a half year). When we compare these results with Cecchetti et al. (1998) we observe that although the half-lives are lower in the Spanish case, the hypothesis of unit root is closer to be accepted.

The results of this econometric analysis show that deviations from PPP at the provincial level are very persistent and that for many provinces and the second sub-sample they may even be considered as permanent. Apparently this is a quite striking result, since it challenges the conventional wisdom that prices behave very similarly between provinces or, at least, relative price adjustment rules out permanent deviations. However, there exists real sources to explain these results and in the next part of this study we explore their relevance.

\section{5. -SOURCES OF DIVERGENCE IN RELATIVE PRICES}

In this section, we present two alternative hypothesis to explain relative price shifts on the basis of relative growth performance. Interestingly, they reach opposite conclusions regarding the correlation between the evolution of relative prices and growth. The crucial differential assumption concerns the nominal wage links among areas with a common currency which, in turn, depend on the depth of economic integration among them.

Both theories are well known. The first is simply the textbook supply-demand schedule expressed in relative terms and the second is the Balassa-Samuelson hypothesis, which has been extensively used to explain real exchange rate shifts, v.g. relative price shifts among countries with different currencies on the basis of sectoral productivity evolutions.

\section{1.-Shifts in relative demand and supply}

The standard textbook supply-demand schedule can be redefined in terms of the (log) relative prices $\left(p_{R E L}=p_{1}-p_{2}\right)$ and $(\log )$ output $\left(y_{R E L}=y_{1}-y_{2}\right)$-expressed in per capita terms- of two regions 1 and 2 , as in the chart 1 . The schedule can also be redefined in terms of $(\log )$ productivity $\left(p_{R E L}=\operatorname{prod}_{1}-\operatorname{prod}_{2}\right)$, with no major change in the intuition ${ }^{(8)}$. The aggregate relative supply curve $(A S)$ is vertical in the long-run, indicating that supply is given by relative

${ }^{(8)}$-If there is full employment productivity and income per capita can be considered as equivalent concepts. 
resources and is inelastic with respect to relative prices ${ }^{(9)}$. On the contrary, the aggregate relative demand curve is negatively sloped, indicating that an increase in domestic relative prices induces a shift in demand away from domestic goods.

Let us assume that output in region 1 tends to grow more, in per capita terms, than in region 2 increasing relative income and productivity; in graphical terms the long-run relative supply curve shifts to the right $\left(A S_{1}\right)$. How do relative prices react to this supply shift?. Based on the textbook schedule, we would not hesitate to say that prices would fall, but the answer actually depends on how nominal wages respond to the changes in productivity.

Higher relative growth in productivity implies, in equilibrium, a relative increase in production factors income. In terms of labour, this implies that an increase in relative productivity is roughly matched by an increase in relative real wages. Denoting relative nominal wages as $w_{R E L}$, this implies that

$$
\text { ? } w_{R E L}-? p_{R E L}=? \operatorname{prod}_{R E L}
$$

The standard textbook case dismisses any induced shift in relative demand, hence implying that the adjustment of real relative wages is thoroughly born by relative prices and that relative nominal wages remain constant. Wage-setting mechanisms operating at the national level is a possible reason for this outcome. In fact, in a deeply integrated area, nominal wages can be thought to have an important national component, either because they are centrally bargained or because they are negotiated sector by sector with national application. Therefore, increases in nominal wages are decided for the whole country, so that nominal relative wages may well remain constant, keeping the demand curve fixed in chart 1; in this case, increases in relative productivity will be reflected in reductions of relative prices.

Of course, in the schedule there may be other sources of demand shifts, leading to a problem of identification. Obvious examples are the effect of pure nominal or monetary shocks or relative fiscal shocks. However, in a country with a common money supply, a deeply integrated financial market and a rather centralised fiscal system these relative demand shifts are not expected to dominate.

All in all, in the context of area-wide wage links, divergence in growth rates between

${ }^{(9)}$-In this simple framework, it is assumed that relative prices do not induce a shift in resources from one region to another. 
regions are expected to induce a negative correlation between relative prices and relative income per capita or productivity.

\section{2.-Sectoral prices and the Balassa-Samuelson hypothesis}

Wage links within the area could be less stringent, leading to relative nominal wage shifts. A relevant case is when relative prices are rigid and it is nominal wages which adjust; expression (6) implies in this case that relative nominal wages increase by the same amount that productivity differentials. In terms of chart 1 , this would imply a outward shift in relative demand, in order to keep relative prices constant.

A final possibility is that the increase in relative nominal wages overshoot relative productivity growth, bringing about -according to expression (6)- an increase in relative prices. Note that, at first sight, this looks like an unreasonable assumption but actually this is the conclusion of the Balassa-Samuelson hypothesis. This hypothesis has been successfully used to explain relative price shifts among countries with different currencies ${ }^{(10)}$; therefore, it is convenient to establish a link between this theory and the previous model.

The Balassa-Samuelson hypothesis is based on the distinction of two types of goods in each economy: tradables and non-tradables. The law of one price presented in section 1 relies on the notion of arbitrage to explain the equality in the evolution of prices. The ability to arbitrage on prices depends on the tradability of goods. Non-tradable goods, typically services, are difficult to arbitrage, so that their prices may diverge between countries or even regions; on the contrary, for tradable goods, as food, manufactures, etc. the law of one price is expected to hold. So, the first assumption of the model is ${ }^{(11)}$ :

$$
? p^{T}{ }_{R E L}=0
$$

where the superscript $T$ refers to the tradable goods. Another crucial assumption is that wage links operate at the sectoral level, due to intersectoral labour mobility but not, as it turns out, at the area-wide level. As a result nominal wages increases are equal among sectors.

${ }^{(10)}$-See Canzoneri et al. (1998) or Alberola \& Tyrväinen (1998)

${ }^{(11)}$-Evidence is far from confirming this prior although Roger \& Jenkins (1995) show that deviations are less persistent in traded goods. Quite strikingly, Cecchetti et al. (1998) show that deviations from PPP in traded goods at the regional level are even larger than for the non-traded goods in the United States. 
Let us now return to expression (6) and apply it to the traded good sector.

$$
? w^{T}{ }_{R E L^{-}} ? p^{T}{ }_{R E L}=\text { ?prod }^{T}{ }_{R E L}
$$

Relative price shifts in tradables are ruled out by the PPP assumption and tradable nominal wages increases are equal to the rest of the economy. Thus, it follows that

$$
? w_{R E L}=\text { ?prod }_{R E L}^{T}
$$

Note that this expression rules out equality of nominal wages among regions (area-wide wage links), unless productivity in tradables grows at the same rate in both regions. Indeed, it tells us that regions with higher productivity growth in tradables will enjoy a higher growth in nominal wages.

Now, solving expression (6) for relative prices and using the result derived in (9) we get the following result for relative prices

$$
? p_{R E L}=? w_{R E L} \text { ?prod }_{R E L}=\text { ?prod }{ }_{R E L}^{T}-\text { ?prod }_{R E L}
$$

The final point to note is a stylised fact in sectoral growth. Due to its higher capital intensity, growth tends to concentrate in the traded good sector and, as a consequence, productivity growth in tradables is usually higher than overall productivity growth, so that faster growing regions will also experience a higher growth in tradable productivity.

Therefore, for high growth regions the final term in (10) is positive, implying that inflation is higher for regions which grow more. Indeed, this result implies that regions with higher growth will observe and increase in relative nominal wages which more than compensates relative productivity growth, implying a large shift in relative aggregate demand -curve $A D_{b s^{-}}$, such as to yield a positive correlation between relative prices and relative growth.

Thus, the implications of the Balassa-Samuelson model, subject to the assumptions they impose, are opposed to the previous conclusions, that is, higher growth should be associated with higher -instead of lower- inflation. The contrasting results essentially depend on the different underlying assumptions on wage determination: national wage links in the aggregate model and sectoral wide links under the Balassa-Samuelson hypothesis. At this point, it is a empirical question to determine which theory dominates in practice.

\section{6. -EMPIRICAL EVIDENCE}


The overview of the theory implies that the empirical analysis can be carried out both at the aggregate and the sectoral level. First, we can test whether the robustness and sign of the link between changes in income per capita or labour productivity and relative prices ${ }^{12}$. Secondly, we could explore the relationship between sectoral productivities and sectoral or relative prices; as a complement, we could also observe the differential behaviour of prices according to its degree of tradability.

However, this analysis is subject to the availability of data, both at the sectoral and at the provincial level and it is indeed this restriction what conditions the scope of this section. First, there is a problem of frecuency of data. Provincial data on real magnitudes (output, employment, income per capita and sectoral output) are provided by the BBV database, which is biannual, and starts in 1962. This is not a big inconvenient because we are interested in the long-run behaviour of the series. The second problem is more serious, since it is related to the availability of adequate price series. Income per capita is adequately deflated by consumer prices, but GDP, productivity or sectoral productivitity should be deflated by the aggregate and sectoral GDP deflators, respectively. These provincial deflators are not available, therefore the choice is between deflating by the national deflators or by the provincial consumer prices ${ }^{(13)}$. It is reasonable to think that provincial GDP deflators track closer the provincial CPIs than the national GDP deflator, so we have opted for the former, as a second-best approximation. An additional problem concerns sectoral prices at the provincial level, which are not available. There are disaggregated provincial CPI indices, but the disaggregation hardly corresponds to the tradable-non tradable distinction, as we will observe.

Having in mind these caveats, we divide the analysis into three parts. In the first part,

\footnotetext{
${ }^{12}$ Here the analysis will be done in terms of differences instead of levels to underline the effects of growth on inflation in the long-run

(13)-There is an approximation to the GDP regional deflator ellaborated by Domenech et al. (1998) which is based on the production structure. However, they assume that sectoral deflators at the regional level are equal to the national deflactors, which is a quite strong assumption.
} 
using panel data estimation we will uncover the relation between variations in relative prices and variations relative aggregates (income per capita and productivity); in the second part, we explore the link between the evolution of relative prices and sectoral productivities. These analysis are analogous and consists basically on an OLS estimation of a panel with fixed individual effects. Finally, the disaggregated provincial CPI indices are briefly analysed.

\section{1.-Income, productivity and relative prices}

The sample includes the years 1962 to 1993 , which is the period covered by the BBV provincial database. Relative prices ( $\mathrm{p}_{\mathrm{RELit}}$ ) are defined in the same way than in section 1, but their frequency is biannual. After differencing, we regress relative inflation ? $q_{i t}$ against three alternatives: growth in relative provincial income per capita, GDP per capita and productivity per employee, deflated by CPI provincial indices ${ }^{(14)}$. There is an additional problem, not mentioned above, which concerns the limited reliability of the BBV database, but for the sample under study there is no alternative. However, for a shorter sample (1980-96) and more aggregated data (regional rather than provincial data) we have repeated the exercise with Regional Accounts data, and the results appear in the appendix 3.

Figures 4.a and 4.b show the scatterplot of provincial relative prices against, respectively, relative income per capita $\left(y_{i t}\right)$ and productivity $\left(\operatorname{prod}_{i t}\right)$. We can observe a clear negative relationship between prices and income and productivity. More formally, we have run the corresponding panel regressions by weighted least squares to account for possible heteroskedasticity, including also a regression for relative per capita GDP $\left(g d p_{i t}\right)$. Moreover, in order to discriminate among short-run, medium-run and long-run relationships we have respectively used period-by-period (2-years) variations, 10-years moving average variations and, finally variations for the whole sample, which collapses to a cross-section analysis. The results appear in the following table:

${ }^{(14)}$-Income per capita is equal to GDP plus labour and capital rents and the difference is relevant at the provincial level. See Alberola and Asdrubali (1997). 


\begin{tabular}{|c|c|c|c|c|}
\hline \multirow{3}{*}{\begin{tabular}{|l|} 
TABLE 3 \\
Slope (t- \\
\end{tabular}} & \multicolumn{4}{|c|}{$\begin{array}{l}\text { REGRESSION ANALYSIS } \\
\quad ? \mathrm{p}_{\text {REL it }}=\mathrm{a}_{\mathrm{i}}+\beta_{\mathrm{i}} ? \mathrm{x}_{\text {it }}+\mathrm{e}_{\mathrm{t}}\end{array}$} \\
\hline & \multicolumn{4}{|c|}{ REGRESSORS $X$} \\
\hline & $Y_{R E L}$ & $G D P_{R E L}$ & $\operatorname{Prod}_{R E L}$ & $\operatorname{Sect}_{R E L}$ \\
\hline Bi-annual & $\begin{array}{l}-0.21 \\
(-13.8)\end{array}$ & $\begin{array}{l}-0.16 \\
(-11.5)\end{array}$ & $\begin{array}{l}-0.16 \\
(-11.5)\end{array}$ & $\frac{-0.01}{(-1.36)}$ \\
\hline 10 Years & $\begin{array}{l}-0.24 \\
(-13.3)\end{array}$ & $\begin{array}{l}-0.20 \\
(-11.3)\end{array}$ & $\begin{array}{l}-0.20 \\
(-12.3)\end{array}$ & $\begin{array}{l}-0.01 \\
(-0.99)\end{array}$ \\
\hline Cross & $\begin{array}{l}-0.19 \\
(-4.20)\end{array}$ & $\begin{array}{c}-0.16 \\
(-3.3)\end{array}$ & $\begin{array}{l}-0.20 \\
(-4.46)\end{array}$ & $\begin{array}{l}0.00 \\
(-0.02)\end{array}$ \\
\hline
\end{tabular}

The results are very similar for any variable and show that there is a robust negative relationship between relative prices and the evolution of income and productivity at the provincial level, endorsing the predictions of the aggregate model.

\section{2.-Sectoral productivity and relative prices}

Sectoral productivity data are available at the provincial level for four sectors. Agriculture and fishing, and manufacturing constitute the tradable sector, while building and services make up the non-tradable sectors. As we have mentioned, there are no data available on these sectoral prices at the provincial level, which has two unfortunate consequences. First, the most direct test of the Balassa-Samuelson hypothesis (contrasting the negative relationship between sectoral productivity and prices at the provincial level) cannot be performed. Second, the unavailability of sectoral prices prevents the proper deflation of sectoral productivity at the provincial level, and we have used national sectoral deflators, thus assuming 'de facto' that sectoral prices behave homogeneously among provinces.

In order to construct the sectoral productivity variable, at the provincial level -denoted as $\operatorname{sect}_{\mathrm{REL}^{-}}$, we have computed the log of relative sectoral productivity at the provincial level and then compared it with the national ratio (subscript ${ }_{n}$ ):

$$
\operatorname{sect}_{R E L}=\frac{\operatorname{prod}^{T}-\operatorname{prod}^{N}}{\operatorname{prod}_{n}^{T}-\operatorname{prod}_{n}^{N}}
$$

Values of relative sectoral productivity higher than one indicates that tradable 
productivity relative to non-tradable productivity is higher than the national ratio. According to the Balassa-Samuelson model, we expect to obtain a positive relation between the

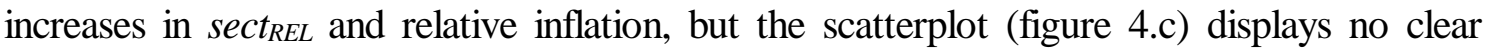
relationship. The regression results, which appear in the last column of table 3 show that the value of the parameter is insignificant.

Therefore, relative sectoral productivities do not allow explaining shifts in relative prices. Recall, however, that in the construction of the variable there is a problem with sectoral deflation at the provincial level ${ }^{(15)}$. In any case, considering this result together with the previous regressions, it can be concluded that the Balassa-Samuelson hypothesis can be rejected for Spain at the provincial level.

\section{3. -Analysis of sectoral prices}

A better assessment of the Balassa-Samuelson hypothesis could be made by examining sectoral prices. The INE provides provincial disaggregated prices for eight sectors since 1977, which appear in the following table. There are two problems with the data. The most serious is that there is not clear correspondence between the sector and the tradability of goods. In the first column, an approximation of the percentage of tradable goods in each sector is presented. Only the food and clothing sector can be considered as genuinely composed of tradable goods and only the last sector, which includes hotels and restaurants can be considered as predominantly non-tradable sector. The second problem regards the reliability of data, since, at the provincial disaggregated level, the size of the survey sample is necessarily small. In fact, for the medicine sector, the pattern of the series is anomalous, and we have ruled out this sector from the analysis. Therefore, the information that is possible to extract is small, but some points can be made.

The descriptive statistics appear in table 4. Following the same procedure as in figure 1,

\begin{tabular}{|c|c|c|c|c|c|c|c|}
\hline \multirow[t]{4}{*}{ TABLE 4} & & \multicolumn{6}{|c|}{ SECTORAL ANALYSIS OF INFLATION SPREADS } \\
\hline & \multicolumn{3}{|c|}{ DESCRIPTIVE ANALYSIS } & \multicolumn{4}{|c|}{ INTEGRATION ANALYSIS } \\
\hline & \multirow[t]{2}{*}{ TRADABLE } & \multirow{2}{*}{$\begin{array}{c}\text { AVERAGE } \\
\text { INFLATION }\end{array}$} & \multirow{2}{*}{$\begin{array}{l}\text { AVERAGE } \\
\text { SPREAD }\end{array}$} & \multicolumn{2}{|c|}{ IMS TEST } & \multicolumn{2}{|c|}{ LL TEST } \\
\hline & & & & $L R$ & $t_{A v g}$ & $t^{*}$ & Half Life \\
\hline FOOD & $100 \%$ & 7.38 & 1.58 & 3.37 & $-1.84 *$ & $-11.7^{*}$ & 2.05 \\
\hline CLOTHING & $100 \%$ & 8.45 & 3.69 & $3.53^{* * *}$ & $-1.8^{* *}$ & $-10.4 \%$ & 14.24 \\
\hline HOUSEHOLD & $71 \%$ & 7.31 & 4.02 & $8.47 *$ & $-2.71 *$ & $-17.4 *$ & 3 \\
\hline TRANSPORT & $60 \%$ & 8.06 & 1.57 & $5.37 *$ & $-2.28 *$ & $-15.8 *$ & 3.93 \\
\hline CULTURE & $50 \%$ & 7.43 & 2.69 & $5.54 *$ & $-2.26 *$ & $-15.4 \%$ & 2.98 \\
\hline MEDICINE & $40 \%$ & 9.53 & - & - & - & - & - \\
\hline HOUSING & $37 \%$ & 7.81 & 4.39 & $6.71 *$ & $-2.39 *$ & $-16.6^{*}$ & 5.27 \\
\hline OTHERS & $13 \%$ & 10.03 & 3.32 & $5.16^{*}$ & $-2.21 *$ & $-15.2 *$ & 2.81 \\
\hline
\end{tabular}


the average inflation and the inflation spread between the three highest and three lowest provinces is computed. The existence of a dual inflation -higher for services and lower for tradable goods, at the national level is a well-documented fact in the Spanish economy (Raymond (1993)), but we cannot observe nitidly this fact in the second column. When we concentrate on the interprovincial differentials (third column), the results are even blurrier. While food has the lowest spread -as expected-, clothing and household display large spreads. Next columns report the order of integrability and persistence of the series resulting from a panel analysis; they show that clothing is the sector with highest persistence, and the IPS test hardly rejects stationarity. For the rest of sectors, but for food, the results do not display a clear relationship between tradability content and the average life.

All in all, although the data are quite inadequate for the analysis, we do not perceive a differential pattern between the behaviour of tradable and non-tradable goods at the provincial level. Therefore, an inference on the Balassa-Samuelson hypothesis from the sectoral prices is not possible. However, we can point out that for some non-tradables, prices are set at the national level. Obvious examples are post and communications, transportation services (included in the transportation sectors). For this type of goods, it is reasonable to think that relative price differentials at the provincial level are smaller than at the national level

\section{4. -Interpretation of the results}

The relationship between the theories of the determination of relative prices and the empirical evidence has shown that the Balassa-Samuelson hypothesis finds scant support at the provincial level: there is no clear relationship between sectoral productivity and relative prices, and sectoral prices at the provincial level are uninformative. This result is in contrast with evidence at the international level. On the contrary, the alternative theory, which predicts a negative relationship between relative productivity gains and relative prices finds strong support in the data.

We have put forward the idea that behind this result is the degree of integration of product and labour markets, in particular that wages are

\begin{tabular}{|l|l|}
\hline \multicolumn{2}{|l|}{ TABLE 6} \\
\\
${ }^{2} \mathrm{w}_{\mathrm{REL}}$ it $=\mathrm{a}_{\mathrm{i}}+{ }{ }_{\mathrm{i}}{ } \mathrm{pro}_{\mathrm{it}}+\mathrm{e}_{\mathrm{t}}$ \\
\multicolumn{2}{|l|}{} \\
\hline Slope (t-ratio) & Prod \\
\hline \multirow{2}{*}{ Bi-annual } & 0.42 \\
& $(12.28)$ \\
& 0.59 \\
& $(12.28$ \\
Cross & 0.01 \\
& $(0.23)$ \\
\hline
\end{tabular}


determined predominantly at the national level, and we dismissed other alternative explanations based on interregional demand shifts. This would imply that, due to the national scope of wage claims, relative nominal wages would not change $? w_{R E L}=0$ (standard textbook case), or that they would change strictly less than relative productivity ? $w_{R E L}{ }^{-}$prod ${ }_{R E L}<0$, as opposed to the Balassa-Samuelson hypothesis in which they increase more than relative productivity (see equation (10)). Therefore, we have regressed relative nominal wages against relative productivity. The results appear in the following table, where the hypothesis that nominal wages grow less than productivity $(\beta \leq 1)$ is clearly not rejected, conforming the theoretical results.

When we turn to the empirical evidence on the determination of wages in Spain, it is surprisingly found in the microeconometric analysis that collective agreements are reached at the sectoral and provincial level (Lorences et al. (1994)). However, as Bentolila \& Jimeno (1998) stress, this institutional arrangement does not traslate into wage dispersion because trade unions -which operate at the national level- make an effort to reduce wage dispersion. The legal framework complements this effort, since wage floors in sectoral wage agreements are binding for individual firms.

All in all these results suggests that national conditions determine the behaviour of provincial wages, explain the results of the empirical analysis and, therefore, confirms that the high degree of economic integration plays a fundamental role in explaining the nature of interprovincial inflation differentials.

\section{7. -CONCLUSIONS}

The objective of this paper has been to study the behaviour of relative prices at the provincial level in Spain, with a view on the possible implications for EMU. We have explored two different questions: The relevance of inflation differential and relative price shifts in a well-established monetary union and the nature of such differential price behaviour.

This study contemplates a quite novel issue in the literature on prices and inflation, such as the behaviour of prices when there are no different monies. Conventional wisdom suggests that the behaviour of prices is homogeneous in a monetary union. However, we have shown that, although the inflation differentials are small, relative price deviations are long lasting. Thus, if we would dare to extrapolate these results to EMU we would conclude that there would be relative price shifts but that they will not be large and, consequently, their real 
effects will not be dramatic.

However, this conclusion is misguiding because the sources of relative price shifts at the provincial level may be different to those that are expected to prevail among countries in EMU. The reason is the differential degree and characteristics of economic integration in one and other case.

EMU is made up of countries with intense trade and capital flows. The Monetary Union will intensify these flows and, more importantly, it will require a substantial effort from the agents to adapt to a more interdependent context. However, common legislation, habits and institutions make economic integration among regions in a country qualitatively different from that which EMU will attain, at least in the medium run. Our theoretical digression has centered on the implications of this type of integration on the labour market mechanisms. It is shown that the national component in wages would be enough to explain the pattern of relative price shifts, in particular, the robust negative relationship between the evolution of income and productivity and prices among Spanish provinces.

This behaviour is in stark contrast with the empirical evidence on real factors behind relative price differentials among countries, which is built around the Balassa-Samuelson model. As we have observed this model takes as basic assumption that wages equalise among sectors but differ among countries. Actually, the current study was intended to complement a previous work on that issue (Alberola \& Tyrväinen (1998)). In that paper, by extrapolating previous trends, an upper bound to inflation differentials in EMU was provided. We intended to provide a lower bound for such differentials by studying relative prices in a long-existing monetary union. In this sense, our results are a disappointment because we cannot extrapolate the Spanish experience to EMU.

In spite of this, we can envisage a case for convergence in the wage mechanisms among EMU countries. Since there is a unique inflation target for the ECB and inflation expectation is a central determinant of wage demands, if trade unions set their wage increases with a look at European-wide inflation, we might observe a certain homogeneity in nominal wage increases.

All in all, some interesting points arise from the analysis. The first is that small inflation differentials and moderate relative price shifts are possible among countries in EMU inasmuch as they exist between provinces in a monetary union. Second, that the nature of these 
differentials will be different from those currently existing among provinces in a country and third, that EMU, as long as it deepens integration among countries will contribute to change, albeit with an undefined lag, the nature of relative price evolutions 
CHART 1.- RELATIVE PRICES AND RELATIVE INCOME

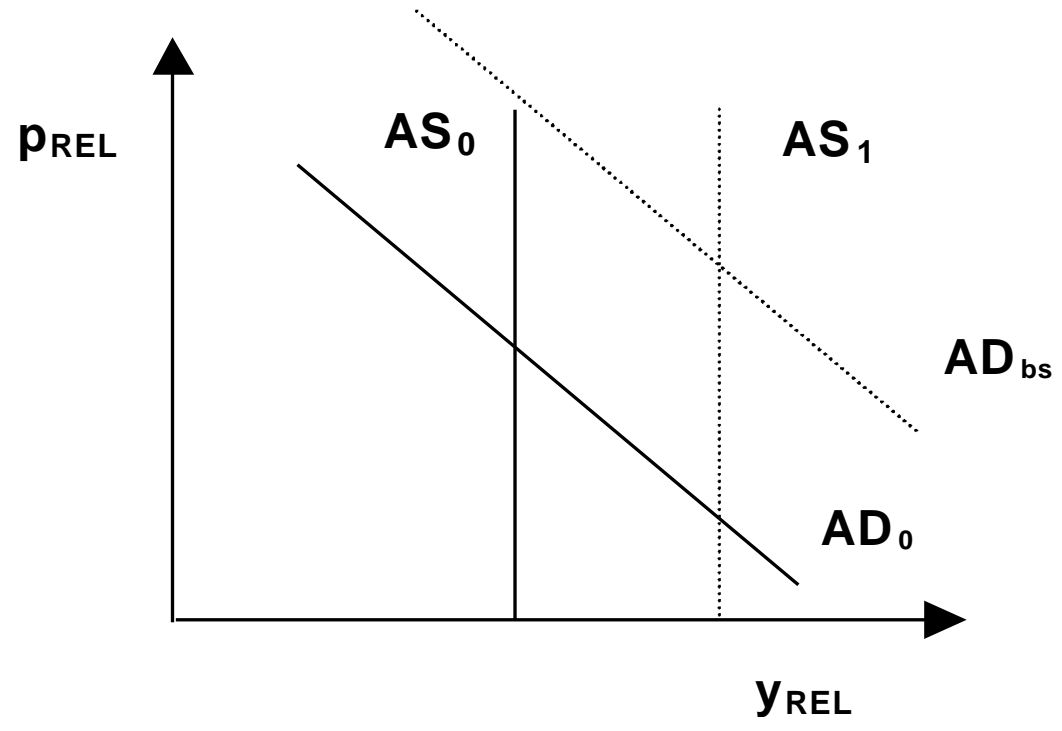


FIGURE 1

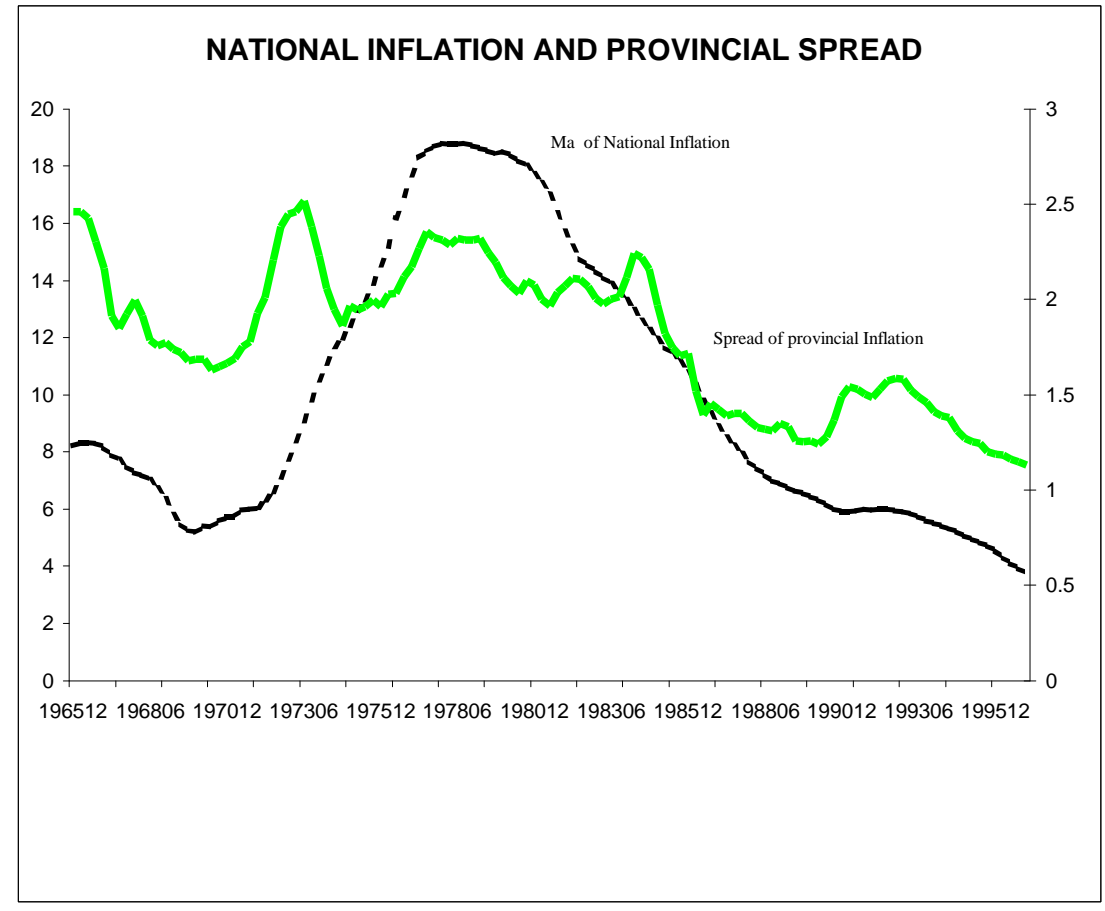

FIGURE 2

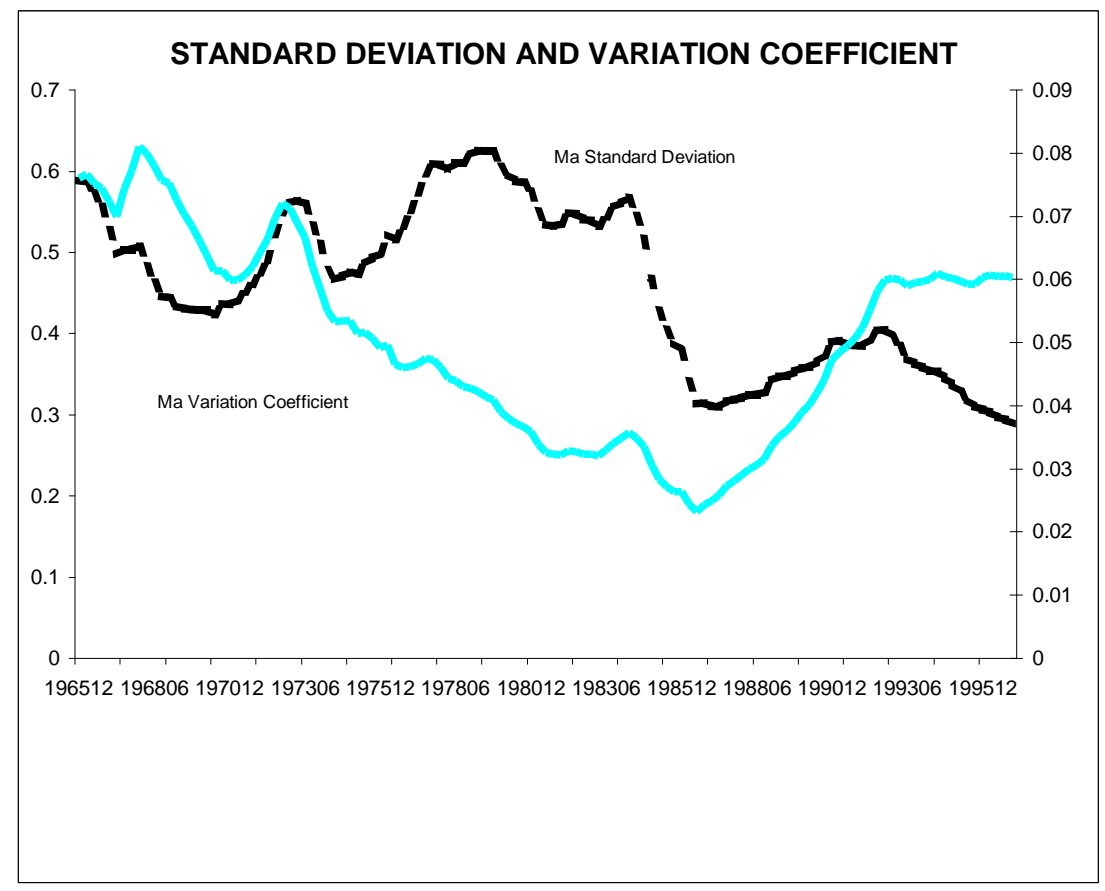


FIGURE 3a

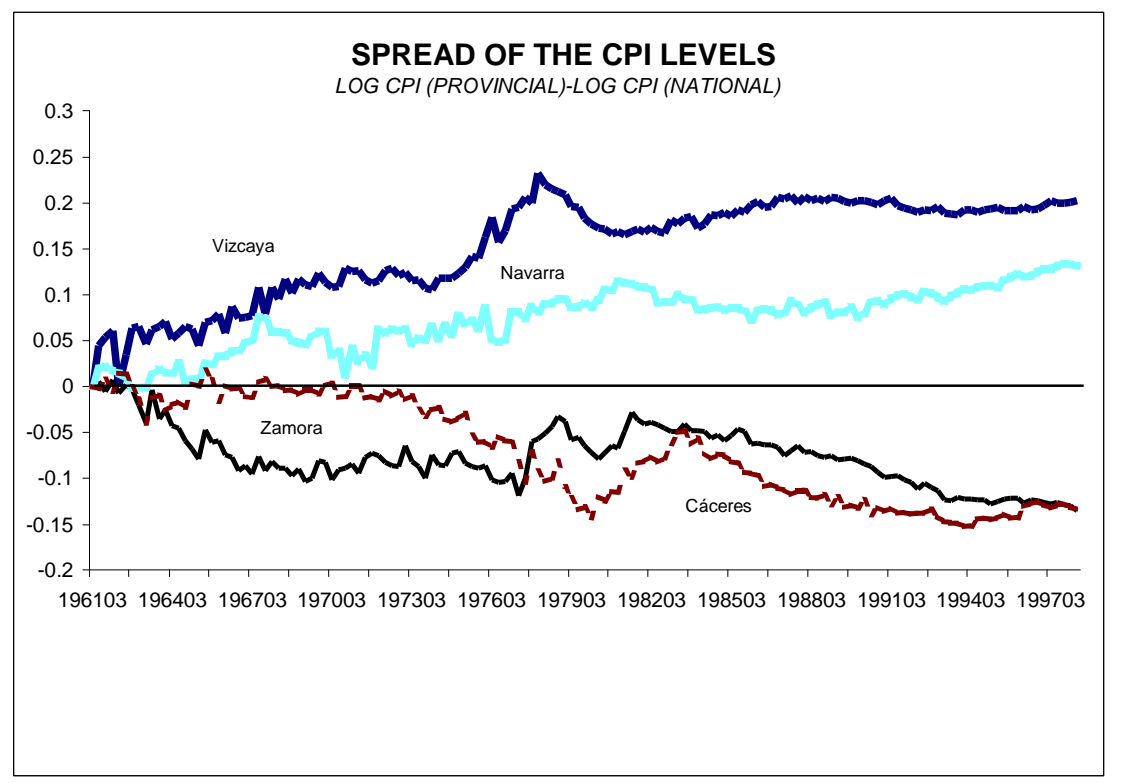

FIGURE 3b

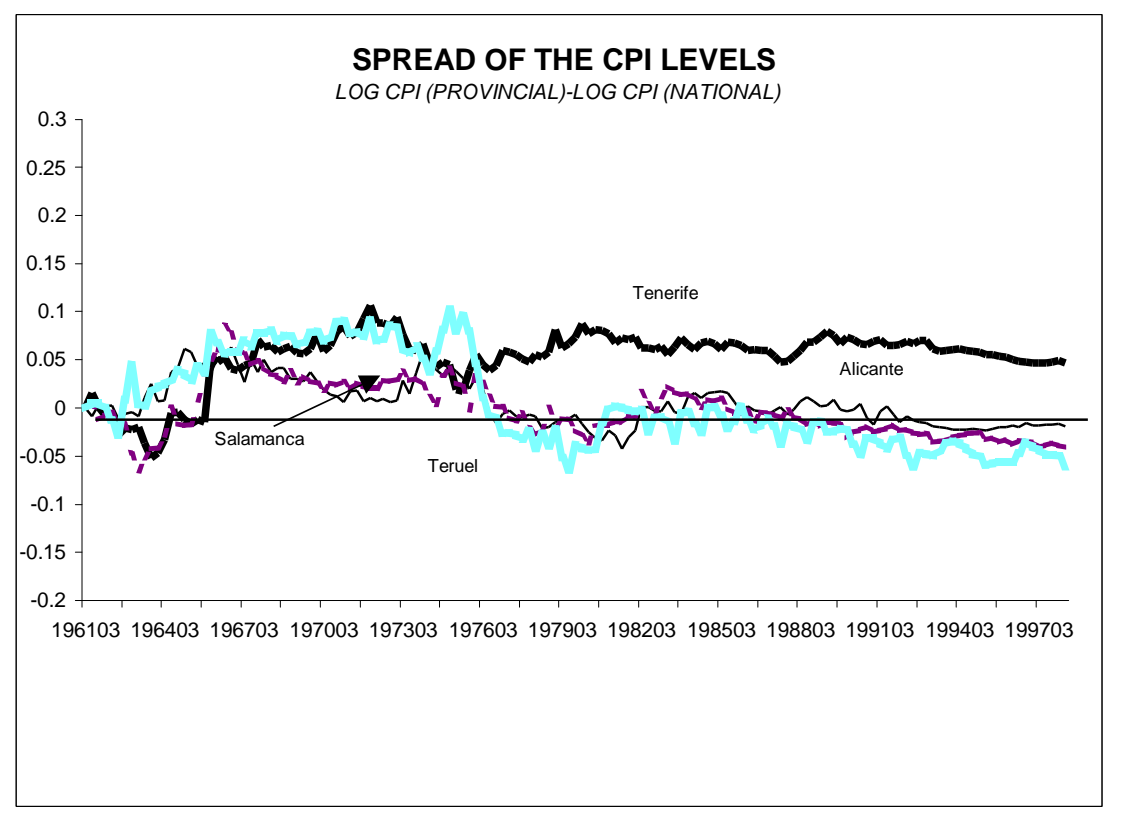


FIGURE 4.a

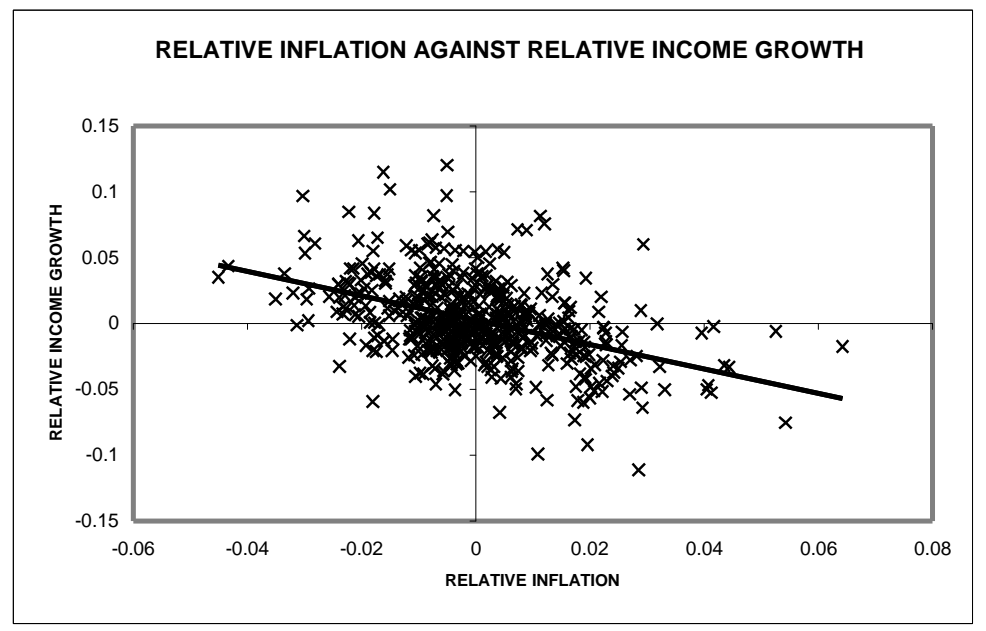

FIGURE 4.b

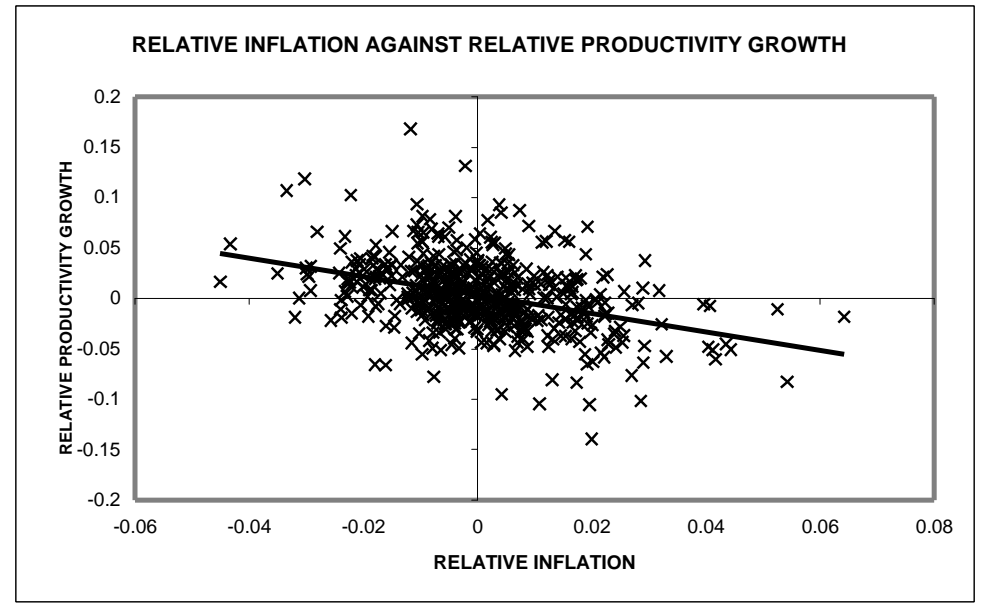

FIGURE 4.c

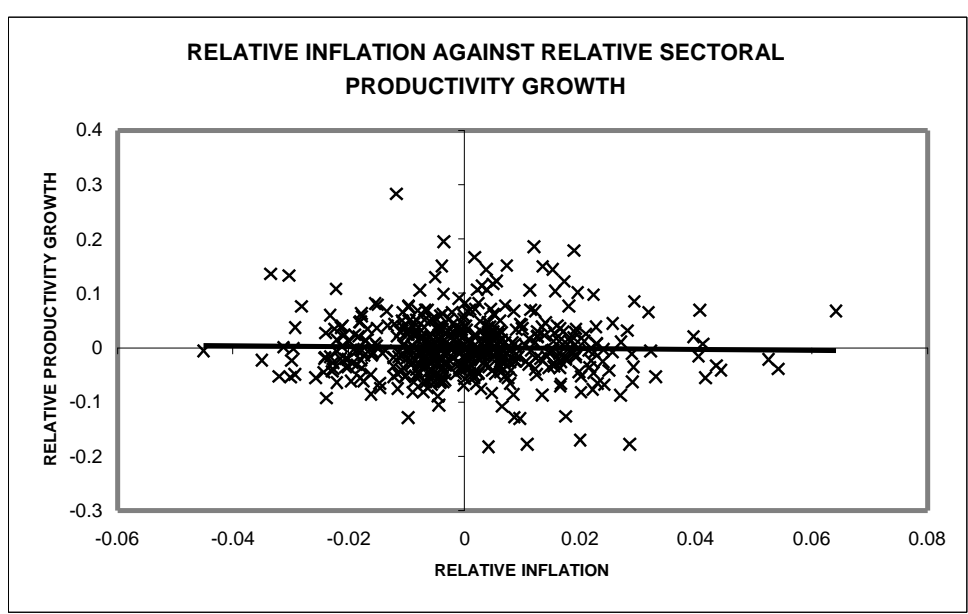




\section{APPENDIX 1. PROVINCIAL ANALYSIS OF RELATIVE PRICES}

\begin{tabular}{|c|c|c|c|c|c|c|c|c|c|c|c|c|c|c|c|}
\hline \multirow[b]{2}{*}{ PROVINCE } & \multirow[b]{2}{*}{$\begin{array}{l}\text { AVERAGE } \\
\text { INFLATION }\end{array}$} & \multicolumn{4}{|c|}{ FULL SAMPLE } & \multicolumn{5}{|c|}{$1960-76$} & \multicolumn{5}{|c|}{$1977-98$} \\
\hline & & LOW & HIGH & ORDER & $\begin{array}{l}\text { HALF } \\
\text { LIFE }\end{array}$ & $\begin{array}{l}\text { AVERAGE } \\
\text { INFLATION }\end{array}$ & LOW & $H I G H$ & ORDER & $\begin{array}{l}H A L F \\
\text { LIFE }\end{array}$ & \begin{tabular}{|c} 
AVERAGE \\
INFLATION
\end{tabular} & LOW & $H I G H$ & ORDER & $\begin{array}{l}\text { HALF } \\
\text { LIFE }\end{array}$ \\
\hline ALAVA & 0.34 & 0 & 66 & $\mathbf{I}(\mathbf{1})$ & 10 & 0.22 & 0 & 15 & I(1) & 10 & 0.45 & $\mathbf{0}$ & 51 & $\mathbf{I}(\mathbf{1})$ & 10 \\
\hline ALBACETE & -0.09 & 41 & $\mathbf{0}$ & $\mathbf{I}(\mathbf{1})$ & 10 & -0.16 & 41 & $\mathbf{0}$ & I(1) & 2 & -0.05 & $\mathbf{0}$ & $\mathbf{0}$ & I(1) & 10 \\
\hline ALICANTE & 0.02 & 1 & 2 & $\mathbf{I}(\mathbf{1})$ & 7 & 0.10 & 0 & 2 & $\mathbf{I}(\mathbf{1})$ & 1 & -0.04 & 1 & $\mathbf{0}$ & I(1) & 2 \\
\hline ALMERIA & 0.02 & $\mathbf{0}$ & $\mathbf{0}$ & $\mathbf{I}(\mathbf{1})$ & 2 & 0.01 & $\mathbf{0}$ & $\mathbf{0}$ & $\mathbf{I}(\mathbf{0}) *$ & 1 & 0.04 & $\mathbf{0}$ & $\mathbf{0}$ & $\mathbf{I}(\mathbf{1})$ & 10 \\
\hline AVILA & 0.07 & $\mathbf{0}$ & 1 & I(1) & 7 & 0.15 & $\mathbf{0}$ & 1 & I(1) & 2 & 0.01 & $\mathbf{0}$ & $\mathbf{0}$ & $\mathbf{I}(\mathbf{0}) *$ & 2 \\
\hline BADAJOZ & 0.11 & 1 & $\mathbf{0}$ & $\mathbf{I}(\mathbf{1})$ & 5 & 0.04 & 1 & $\mathbf{0}$ & I(1) & 3 & 0.17 & $\mathbf{0}$ & $\mathbf{0}$ & $\mathbf{I}(\mathbf{0})$ & 2 \\
\hline BALEARES & 0.24 & $\mathbf{0}$ & 16 & $\mathbf{I}(\mathbf{0})$ & 1 & 0.21 & $\mathbf{0}$ & 12 & I(1) & 1 & 0.25 & $\mathbf{0}$ & 4 & I(1) & 10 \\
\hline BARCELONA & 0.28 & $\mathbf{0}$ & 41 & I(1) & 10 & 0.25 & $\mathbf{0}$ & 15 & I $(0)$ & $\mathbf{0}$ & 0.32 & $\mathbf{0}$ & 26 & I(1) & 10 \\
\hline BURGOS & 0.16 & 1 & 6 & $\mathbf{I}(\mathbf{1})$ & 10 & 0.06 & 1 & 0 & $\mathbf{I}(\mathbf{1})$ & 7 & 0.23 & $\mathbf{0}$ & 6 & I(1) & 10 \\
\hline CACERES & -0.28 & 94 & $\mathbf{0}$ & $\mathbf{I}(\mathbf{1})$ & 10 & -0.06 & 9 & $\mathbf{0}$ & I(1) & 9 & -0.46 & 85 & $\mathbf{0}$ & $\mathbf{I}(\mathbf{1})$ & 10 \\
\hline CADIZ & 0.29 & $\mathbf{0}$ & 70 & $\mathbf{I}(\mathbf{1})$ & 10 & 0.06 & $\mathbf{0}$ & 1 & I(1) & 3 & 0.50 & $\mathbf{0}$ & 69 & I(1) & 2 \\
\hline CASTELLON & 0.32 & $\mathbf{0}$ & 59 & I(1) & 4 & 0.29 & $\mathbf{0}$ & 21 & I(1) & 2 & 0.38 & $\mathbf{0}$ & 38 & I(1) & 10 \\
\hline C. REAL & 0.24 & $\mathbf{1}$ & 37 & $\mathbf{I}(\mathbf{1})$ & 10 & 0.08 & 1 & 2 & I(1) & 2 & 0.37 & $\mathbf{0}$ & 35 & I(1) & 7 \\
\hline CORDOBA & 0.31 & 1 & 58 & $\mathbf{I}(\mathbf{0}) *$ & 2 & 0.34 & 1 & 55 & $\mathbf{I}(\mathbf{0})$ & 1 & 0.29 & $\mathbf{0}$ & 3 & I(1) & 7 \\
\hline CORUÑA & -0.05 & 11 & $\mathbf{0}$ & I(1) & 4 & 0.00 & 3 & $\mathbf{0}$ & I(1) & 10 & -0.08 & 8 & $\mathbf{0}$ & I(1) & 2 \\
\hline CUENCA & -0.12 & 39 & 3 & $\mathbf{I}(\mathbf{1})$ & 7 & -0.06 & 22 & 3 & $\mathbf{I}(\mathbf{1})$ & 10 & -0.17 & 17 & $\mathbf{0}$ & I(1) & 9 \\
\hline GERONA & 0.08 & 0 & 8 & I(1) & 10 & 0.19 & $\mathbf{0}$ & 8 & I(1) & 4 & 0.02 & $\mathbf{0}$ & $\mathbf{0}$ & I(1) & 10 \\
\hline GRANADA & 0.14 & 1 & $\mathbf{0}$ & $\mathbf{I}(\mathbf{0})$ & 3 & 0.12 & 1 & $\mathbf{0}$ & I(1) & 2 & 0.18 & $\mathbf{0}$ & $\mathbf{0}$ & $\mathbf{I}(\mathbf{0}) *$ & 2 \\
\hline GUADALAJARA & 0.13 & $\mathbf{0}$ & 3 & $\mathbf{I}(\mathbf{1})$ & 2 & 0.16 & 0 & 3 & $\mathbf{I}(\mathbf{0})$ & 1 & 0.11 & $\mathbf{0}$ & $\mathbf{0}$ & I(1) & 10 \\
\hline GUIPUZCOA & -0.27 & 120 & $\mathbf{0}$ & $\mathbf{I}(\mathbf{1})$ & 10 & -0.13 & 35 & 0 & $\mathbf{I}(\mathbf{1})$ & 10 & -0.36 & 85 & 0 & $\mathbf{I}(\mathbf{1})$ & 4 \\
\hline HUELVA & 0.18 & 0 & 5 & $\mathbf{I}(\mathbf{0})$ & 1 & 0.18 & $\mathbf{0}$ & 5 & $\mathbf{I}(\mathbf{0})$ & 1 & 0.17 & $\mathbf{0}$ & 0 & I(1) & 2 \\
\hline HUESCA & 0.27 & 0 & 27 & I(1) & 5 & 0.23 & 0 & 23 & I(1) & 10 & 0.31 & 0 & 4 & I(1) & 2 \\
\hline JAEN & -0.07 & 26 & 1 & $\mathbf{I}(\mathbf{1})$ & 10 & 0.07 & 3 & 1 & $\mathbf{I}(\mathbf{1})$ & 2 & -0.17 & 23 & 0 & $\mathbf{I}(\mathbf{0})$ & 0 \\
\hline LEON & -0.12 & 43 & o & I(1) & 10 & -0.05 & 17 & 0 & I(1) & 7 & -0.17 & 26 & o & I(1) & 10 \\
\hline LERIDA & 0.07 & 1 & o & $\mathbf{I}(\mathbf{0})$ & 1 & 0.05 & 1 & 0 & $\mathbf{I}(\mathbf{0})$ & o & 0.11 & 0 & o & I(1) & 2 \\
\hline LOGROÑO & 0.18 & 0 & 8 & $\mathbf{I}(\mathbf{1})$ & 4 & 0.20 & 0 & 8 & I(1) & 9 & 0.19 & 0 & o & $\mathbf{I}(\mathbf{1})$ & 10 \\
\hline LUGO & -0.19 & 66 & 0 & $\mathbf{I}(\mathbf{1})$ & 10 & 0.02 & 0 & 0 & $\mathbf{I}(\mathbf{0})$ & 0 & -0.39 & 66 & 0 & $\mathbf{I}(\mathbf{1})$ & 10 \\
\hline MADRID & 0.21 & 4 & 2 & I(1) & 5 & 0.15 & 4 & 2 & I(1) & 10 & 0.25 & 0 & 0 & $\mathbf{I}(\mathbf{0}) *$ & 1 \\
\hline MALAGA & 0.11 & 3 & o & I(1) & 10 & 0.01 & 3 & 0 & I(1) & 10 & 0.19 & o & $\mathbf{0}$ & I(1) & 2 \\
\hline MURCIA & 0.05 & 3 & 0 & $\mathbf{I}(\mathbf{0})$ & 1 & 0.03 & 3 & 0 & $\mathbf{I}(\mathbf{0}) *$ & 1 & 0.08 & o & o & I(1) & 2 \\
\hline NAVARRA & 0.29 & 0 & 33 & I(1) & 10 & 0.16 & 0 & 1 & I(1) & 5 & 0.40 & 0 & 32 & I(1) & 10 \\
\hline ORENSE & 0.12 & 0 & 3 & $\mathbf{I}(\mathbf{0})^{*}$ & 2 & 0.12 & o & 3 & $\mathbf{I}(\mathbf{0})$ & 0 & 0.12 & $\mathbf{0}$ & 0 & $\mathbf{I}(\mathbf{1})$ & 10 \\
\hline ASTURIAS & 0.23 & 1 & 13 & I(1) & 7 & 0.12 & 1 & 0 & I(1) & 3 & 0.34 & 0 & 13 & I(1) & 4 \\
\hline PALENCIA & 0.11 & 0 & $\mathbf{0}$ & $\mathbf{I}(\mathbf{1})$ & 3 & 0.12 & 0 & 0 & I(1) & 1 & 0.10 & o & $\mathbf{0}$ & I(1) & 10 \\
\hline G. CANARIA & 0.08 & 12 & 2 & I(1) & 7 & -0.02 & 12 & 2 & I(1) & 1 & 0.15 & o & o & I(1) & 10 \\
\hline PONTEVEDRA & 0.16 & 2 & 38 & I(1) & 10 & 0.30 & 2 & 38 & $\mathbf{I}(\mathbf{0})$ & 1 & 0.02 & 0 & 0 & I(1) & 10 \\
\hline SALAMANCA & -0.01 & 6 & 2 & I(1) & 5 & 0.07 & 6 & 2 & I(1) & 3 & -0.07 & 0 & o & I(1) & 10 \\
\hline TENERIFE & 0.04 & 34 & 1 & I(1) & 10 & -0.13 & 33 & 1 & I(1) & 2 & 0.21 & 1 & 0 & I(1) & 4 \\
\hline SANTANDER & 0.12 & 4 & 1 & I(1) & 5 & 0.16 & 4 & 1 & I(1) & 2 & 0.09 & o & o & I(1) & 10 \\
\hline SEGOVIA & 0.05 & 0 & 1 & I(1) & 10 & 0.10 & 0 & 1 & I(1) & 3 & 0.02 & 0 & 0 & I(1) & 10 \\
\hline SEVILLA & -0.14 & 48 & $\mathbf{0}$ & $\mathbf{I}(\mathbf{0})$ & 1 & -0.12 & 23 & o & $\mathbf{I}(\mathbf{0})$ & 1 & -0.14 & 25 & $\mathbf{0}$ & I(1) & 2 \\
\hline SORIA & 0.16 & 0 & 1 & I(1) & 10 & 0.00 & 0 & 0 & I $(\mathbf{0})$ & 0 & 0.28 & 0 & 1 & I(1) & 4 \\
\hline TARRAGONA & 0.03 & 1 & $\mathbf{0}$ & $\mathbf{I}(\mathbf{0})$ & 1 & 0.04 & 1 & 0 & $\mathbf{I}(\mathbf{1})$ & 1 & 0.02 & 0 & 0 & $\mathbf{I}(\mathbf{1})$ & 1 \\
\hline TERUEL & 0.02 & 5 & 4 & I(1) & 10 & 0.20 & 2 & 4 & I(1) & 2 & -0.12 & 3 & o & I(1) & 5 \\
\hline TOLEDO & -0.12 & 17 & o & $\mathbf{I}(\mathbf{0})$ & 1 & -0.06 & 12 & 0 & $\mathbf{I}(\mathbf{0})$ & o & -0.16 & 5 & o & $\mathbf{I}(\mathbf{0})^{*}$ & 5 \\
\hline VALENCIA & 0.03 & 20 & $\mathbf{0}$ & I(1) & 4 & -0.06 & 20 & 0 & I(1) & 2 & 0.10 & 0 & o & I(1) & 2 \\
\hline VALLADOLID & 0.33 & $\mathbf{0}$ & 82 & I(1) & 5 & 0.24 & $\mathbf{0}$ & 29 & I(1) & 17 & 0.41 & 0 & 53 & I(1) & 10 \\
\hline VIZCAYA & 0.61 & 0 & 141 & I(1) & 10 & 0.39 & 0 & 56 & I(1) & 10 & 0.76 & 0 & 85 & I(1) & 1 \\
\hline ZAMORA & -0.30 & 132 & 0 & I(1) & 5 & -0.27 & 52 & 0 & $\mathbf{I}(\mathbf{0}) *$ & 2 & -0.34 & 80 & 0 & I(1) & 10 \\
\hline ZARAGOZA & 0.20 & 0 & 5 & $\mathbf{I}(\mathbf{0}) *$ & 3 & 0.10 & 0 & 0 & $\mathrm{I}(\mathbf{0}) *$ & 1 & 0.26 & 0 & 5 & I (1) & 7 \\
\hline
\end{tabular}




\section{APPENDIX 2. IMPLEMENTATION OF PANEL DATA TESTS}

We assume that each variable $p_{\text {RELit }}$ follows a stochastic process like:

$$
? \mathrm{p}_{\mathrm{REL} \text { it }}=\mathrm{a}_{\mathrm{i}}+\beta_{\mathrm{i}} \mathrm{p}_{\mathrm{REL} \mathrm{it}-1}+\sum_{j=1}^{\mathrm{k}_{\mathrm{i}}+1} ?_{\mathrm{ij}} \Delta \mathrm{p}_{\mathrm{REL} \mathrm{it}-\mathrm{j}}+\mathrm{u}_{\mathrm{it}}
$$

Where the $\mathrm{k}_{\mathrm{i}}$ are determined like in the ADF test according to the significance lags, $\alpha_{\mathrm{i}}$ are individual effects, and the $u_{i}$ is independently distributed across individuals. The two tests differ basically in the treatment of $\beta_{i}$.

\section{LEVIN AND LIN TEST}

The null hypothesis is that all $\beta_{i}$ are equals to a single $\beta$, different from zero To implement the test the next steps are required:

Step 1: Subtract cross-section averages from the data. This is because we assume that data are generated independently across individuals and implies that:

$$
\mathrm{p}_{\mathrm{REL} \text { it }}^{*}=\mathrm{p}_{\mathrm{REL} \mathrm{it}}-\frac{1}{\mathrm{~N}} \sum_{i=1}^{N} \mathrm{p}_{\mathrm{REL} \mathrm{it}}
$$

During the next sections we will use $p_{\text {RELit }}$ to refer to the adjusted data pREL $_{\text {it. }}$.

Step 2: Compute orthogonalized first differences and lagged levels for each individual, and normalise them by the estimated residual standard error. Levin and Lin make use of the equivalence of the standard ADF regression (A.1) and the following regression:

$$
\widehat{\mathrm{e}}_{\mathrm{it}}=\beta_{i} \widehat{\mathrm{v}}_{\mathrm{it}}+\varepsilon_{\mathrm{it}}
$$

where

$$
\widehat{\mathrm{e}}_{\mathrm{it}}=? \mathrm{p}_{\text {REL it }}-\widehat{\mathrm{a}}_{\mathrm{i}}-\sum_{\mathrm{j}=1}^{\mathrm{K}_{\mathrm{i}}} ?_{\mathrm{ij}} \Delta \mathrm{p}_{\text {REL it }-\mathrm{j}}
$$




$$
\widehat{\mathrm{V}}_{\mathrm{it}}=\mathrm{p}_{\text {REL it }}-\widehat{\mathrm{a}}_{\mathrm{i}}-\sum_{\mathrm{j}=1}^{\mathrm{K}_{\mathrm{i}}} ?_{\mathrm{ij}} \Delta \mathrm{p}_{\mathrm{REL} \mathrm{it}-\mathrm{j}}
$$

From the residual regression we obtain:

$$
\begin{aligned}
& \widehat{\mathrm{S}}_{\mathrm{e}_{\mathrm{i}}}^{2}=\frac{1}{\mathrm{~T}-\mathrm{k}_{\mathrm{i}}-1} \sum_{\mathrm{t}=\mathrm{k}_{\mathrm{i}}+2}^{\mathrm{T}}\left(\widehat{\mathrm{e}}_{\mathrm{it}}-\widehat{\mathrm{d}}_{\mathrm{i}} \widehat{\mathrm{V}}_{\mathrm{it}-1}\right)^{2} \\
& \widetilde{\mathrm{e}}_{\mathrm{it}}=\frac{\widehat{\mathrm{e}}_{\mathrm{it}}}{\widehat{\mathrm{S}}_{\mathrm{e}_{\mathrm{i}}}} \\
& \widetilde{\mathrm{V}}_{\mathrm{it}-1}=\frac{\widehat{\mathrm{V}}_{\mathrm{it}-1}}{\widehat{\mathrm{S}}_{\mathrm{e}_{\mathrm{i}}}}
\end{aligned}
$$

Step 3: Estimate the ratio of long run to short-run standard deviations for each individual, and then calculate the average ratio for the panel. Under the null hypothesis the normalised long-run variance $\mathrm{s}_{\mathrm{q}_{\mathrm{i}}^{2}}^{2}=\lim _{\mathrm{T} \rightarrow \infty} \mathrm{E}\left(\mathrm{q}_{\mathrm{iT}}^{2} / \mathrm{T}\right)$ can be estimated as follows:

$$
\sigma_{q_{i}}^{2}=\frac{1}{\mathrm{~T}-1} \sum_{\mathrm{t}=2}^{\mathrm{T}} \Delta \mathrm{p}_{\mathrm{REL} i t}^{2}+2 \sum_{\mathrm{L}=1}^{\mathrm{K}} w_{K l}\left(\frac{1}{\mathrm{~T}-1} \sum_{\mathrm{t}=2+\mathrm{L}}^{\mathrm{T}} \Delta \mathrm{p}_{\mathrm{REL} i t} \Delta \mathrm{p}_{\mathrm{REL} i t-L}\right) \quad \mathrm{A} .8
$$

Where the sample covariances weights $\mathrm{w}_{\mathrm{KL}}$ are the Bartlett weights $\mathrm{w}_{\mathrm{KL}}=\mathrm{L} /(\mathrm{K}+1)$ and the $\mathrm{K}$ should be chosen proportional to $\mathrm{T}^{16}$ This correction is to ensure a non-negative value of the variance and is proposed by Newey and West (1987).

Now for each individual we can estimate the ratio of long-run standard deviation as follows:

$$
\widehat{S}_{\mathrm{i}}=\frac{\sigma_{\mathrm{q}_{\mathrm{i}}}}{\mathrm{s}_{\mathrm{e}_{\mathrm{i}}}}
$$

Then we define the average standard deviation ratio as $\mathrm{S}_{\mathrm{N}}=\frac{1}{N} \sum_{i=1}^{N} \widehat{\mathrm{s}}_{\mathrm{i}}$, and the average

${ }^{16}$ Levin and Lin (1993) suggested in his tables values of the $\mathrm{k}$ for some selected time dimensions. 
variance ratio as $\mathrm{V}_{\mathrm{N}}=\frac{1}{N} \sum_{i=1}^{N} \widehat{\mathrm{s}}_{\mathrm{i}}^{2}$.

Step 4: Compute the panel statistics. Under the null hypothesis the residuals from A.6 and A.7 should be independent for each individual in the panel. Performing the following panel regression can test this:

$$
\tau_{\mathrm{it}}=\beta \nabla_{\mathrm{it}-1}+\varepsilon_{\mathrm{it}}
$$

Notice that $\mathrm{NT}^{*}$ observations are used in this regression, where $\mathrm{T}^{*}=\left(\mathrm{T}-\mathrm{K}^{*}-1\right)$ and $\mathrm{K}^{*}$ is the average lag order for the individual ADF regressions (the average of the $\mathrm{k}_{\mathrm{i}}$ ). From A.10 we can obtain the next statistics:

$$
\begin{aligned}
& \beta=\frac{\sum_{i=1}^{N} \sum_{t=2+k_{i}}^{T} \widetilde{\nabla}_{i t-1} \widetilde{e}_{i t}}{\sum_{i=1}^{N} \sum_{t=2+k_{i}}^{T} \widetilde{\nabla}_{i t-1}^{2}} \\
& \widehat{\mathrm{S}}_{\mathrm{e}}=\left[\frac{1}{\mathrm{NT} *} \sum_{\mathrm{i}=1}^{\mathrm{N}} \sum_{\mathrm{t}=2+\mathrm{k}_{\mathrm{i}}}^{\mathrm{T}}\left(\widetilde{\mathrm{e}}_{\mathrm{it}}-\beta \nabla_{\mathrm{it}-1}\right)^{2}\right]^{1 / 2} \\
& \operatorname{RSE}(\beta)=\varsigma_{\mathrm{e}}\left[\sum_{\mathrm{i}=1}^{\mathrm{N}} \sum_{\mathrm{t}=2+\mathrm{k}_{\mathrm{i}}}^{\mathrm{T}} \nabla_{\mathrm{it}-1}{ }^{2}\right]^{1 / 2} \\
& \mathrm{t}_{\beta}=\frac{\beta}{\operatorname{RSE}(\beta)} \\
& \mathrm{t} *_{\beta}=\frac{\mathrm{t}_{\mathrm{d}}-\mathrm{NT}{ }^{*} \widehat{\mathrm{S}}_{\mathrm{NT}} \sigma_{\varepsilon}^{-2} \operatorname{RSE}(\widehat{\beta}) \mu_{\mathrm{mT}}^{*}}{\sigma_{\mathrm{mT} *}^{*}}
\end{aligned}
$$

The mean adjustment $\mu^{*}{ }_{\mathrm{m}}^{*}$ and standard deviation adjustment $\sigma^{*}{ }_{\mathrm{m} T^{*}}$ can be found in the Table 1 from Levin and Lin (1993). The $t$ adjusted $t_{\beta}{ }^{*}$, in A.15 is distributed under the null as a $\mathrm{N}(0,1)$, and the standard normal distribution tables can be used to test the null hypothesis. 


\section{IM, PESARAN AND SHIN TEST}

The null hypothesis in this test is identical to the Levin and Lin test but now the $\beta_{\mathrm{i}}$ may differ among individuals. This test consist in the next steps:

Step 1: Subtract cross-section averages from the data. This is identically to step 1 in Levin and Lin test.

Step 2: Run restricted and unrestricted versions of the data generating process. That is:

$$
\begin{aligned}
& ? \mathrm{p}_{\text {REL it }}=\mathrm{a}_{\mathrm{i}}+\beta_{\mathrm{i}} \mathrm{p}_{\text {REL it }-1}+\sum_{\mathrm{j}=1}^{\mathrm{k}_{\mathrm{i}}} ?_{\mathrm{ij}} \mathrm{p}_{\text {REL } \mathrm{t}-\mathrm{j}}+\varepsilon_{\mathrm{i}, \mathrm{t}} \\
& ? \mathrm{p}_{\text {REL it }}=\mathrm{a}_{\mathrm{i}}+\sum_{\mathrm{j}=1}^{\mathrm{k}_{\mathrm{i}}} ?_{\mathrm{ij}} \mathrm{p}_{\text {REL } \mathrm{t}-\mathrm{j}}+\mathrm{u}_{\mathrm{i}, \mathrm{t}}
\end{aligned}
$$

Then estimate the error variances by :

$$
\begin{aligned}
& \sigma_{\mathrm{i}}^{2}=\frac{1}{\mathrm{~T}} \sum_{\mathrm{t}=1}^{\mathrm{T}} \varepsilon_{\mathrm{i}, \mathrm{t}}{ }^{2} \\
& \sigma_{\mathrm{i}}^{2}=\frac{1}{\mathrm{~T}} \sum_{\mathrm{t}=1}^{\mathrm{T}} \hat{u}_{\mathrm{i}, \mathrm{t}}{ }^{2}
\end{aligned}
$$

Step 3: compute the individual and mean LR ratio. The individual LR ratio is computed ,as usual, as:

$$
\mathrm{LR}_{\mathrm{i}}=\mathrm{T}\left(\ln \widetilde{\mathrm{s}}_{\mathrm{i}}^{2}-\ln \widetilde{\mathrm{s}}_{\mathrm{i}}^{2}\right)
$$

The average $L R$ ratio is just the average of the individual LR ratio:

$$
\mathrm{LR}=\frac{1}{\mathrm{~N}} \sum_{\mathrm{i}=1}^{\mathrm{N}} \mathrm{LR}_{\mathrm{i}}
$$

In the same way, if $t_{i}$ is the studentized coefficient from the ADF test we can compute as 
in the last equation an average $t_{\text {avg. }}$. Both the average $t$ and the average LR follow under the null hypothesis a non-standard distribution. Critical values are tabulated by Monte Carlo simulations and reported in Im, Pesaran and Shin (1997).

\section{A.3.- REGRESSIONS WITH REGIONAL ACCOUNTS DATA}

The empirical analysis in section 5 has used as regressors the BBV database, which is the only available at disaggregated level for Spain for the sample we have used. However, the statistical accuracy of this database has been object of discussion.

Since this may condition the reliability of our results we perform here the same sort of analysis, but using GDP data -deflated by regional CPIs from the Regional Accounts. These data cover the 17 Spanish regions from 1980 to 1996, with annual frequency, that is, the sample period is shorter and the geographical disaggregation is lower than with the previous database.

The next table shows that the results do not change in qualitative terms. The sign is significantly negative although the slope of the curve is lower than in the previous regressions in the three cases considered.

\begin{tabular}{|l|l|}
\hline \multicolumn{2}{|c|}{ REGRESSION } \\
? $\mathrm{p}_{\mathrm{REL}}$ it $={ }^{2}{ }_{\mathrm{i}}+{ }^{\beta}{ }_{\mathrm{i}}{ }^{2} \mathrm{Y}_{\mathrm{RE}}{ }_{\mathrm{it}}+\mathrm{e}_{\mathrm{t}}$ \\
\hline \multicolumn{2}{|c|}{} \\
\hline Slope (t-ratio) & YREL \\
\hline \multirow{2}{*}{ Bi-annual } & -0.05 \\
& $(-4.95)$ \\
10 Years & -0.12 \\
& $(-5.63)$ \\
Cross & -0.13 \\
& $(-2.38)$ \\
\hline
\end{tabular}




\section{REFERENCES}

ALBEROLA,E., P.ASDRUBALI (1997), How do Countries Smooth Macroeconomic Disturbances. Spain (1973-93), Banco de España, WP 9724.

ALBEROLA,E., T.TYRVAINEN (1998), Is there Scope for Inflation Differentials in EMU?, Moneda y Crédito (forthcoming).

BALASSA, B. (1964), The purchasing power parity doctrine: A reappraisal, Journal of Political Economy, 72,pp.584-96.

BERGSTRAND,J.H. (1991). Structural Determinants of Real Exchange Rates and National Price Levels: Some Empirical Evidence, American Economic Review, 81,pp.325-34.

CAMPBELL,J.Y., P.PERRON (1991), Pitfalls and Opportunities: What Macroeconomists Should Know about Unit Roots, NBER Macroeconomics Annual,6.

CANZONERI, M.R. CUMBY, B.DIBA,G.EUDEY (1998), Trends in European Productivity: Implications for Real Exchange Rates and Inflation Differentials, forthcoming Journal of International Economics.

CECCHETTI, S.G., N.C.MARK. R. SONORA (1998), Price Level Convergence Among United States Cities: Lessons for the European Central Bank, Öesterreicher NationalBank $W P, 32$

DOMENECH,R., F.J.ESCRIBA, M.J.MURGUI (1998), Cambios en Precios Relativos y Crecimiento Económico en las Regiones Españolas, Dirección General de Análisis y Programación Presupuestaria, DT.98006.

ENGEL,C., J.H.ROGERS (1996), How Wide is the Border?, American Economic Review, $86,1112-15$ 
GIOVANNINI.A. (1988), Exchange Rates and Traded Goods Prices, Journal of International Economics, 24,pp,45-68.

IM,K.S., M.H.PESARAN, Y.SHIN (1997), Testing for Unit Roots in Heterogeneous Panels, mimeo, Trinity College, Cambridge.

ISARD,P. (1977), How Far can We Push the 'Law of One Price', American Economic Review,67, December pp.942-8.

JIMENO,J.F., S.BENTOLILA (1998), Regional Unemployment Persistence (Spain 197694), Labour Economics,5,pp.25-51

KENDALL,M.G. (1954), Note on the Bias in the Estimation of Autocorrelation, Biometrika,41,pp.403-4.

LEVIN,A.,C.F.LIN (1993), Unit Root Tests in Panel Data: New Results, University of California, San Diego, Discussion Papers, 93-56.

LORENCES,J., V.FERNANDEZ, C.RODRIGUEZ (1994), Diferencias Interterritoriales de Salarios y Negociación Colectiva, Boletín Económico, Banco de España, Octubre.

MaCDONALD, R. (1998), What Do We Really Know About Real Exchange Rates?, Öesterreicher NationalBank WP, 28

OBSTFELD,M., K.ROGOFF (1995), Foundations of International Macroeconomics, MIT Press.

PARSLEY,D., S.J.WEI (1996), Convergence to the Law of One Price without Trade Barriers or Currency Fluctuations, Quarterly Journal of Economics, 111, pp.1211-36. 
RAYMOND,J.L., I.MAULEON (1996), Inflation in Spain: a Two-Sector Approach, in de Grauwe, Micossi, Tullio (eds.) Inflation and wage behaviour in Europe, Clarendon Press.

ROGERS,J.H., M.A.JENKINS (1995), Haircuts or hysteresis?. Sources of movements in real exchange rates, Journal of International Economics,38,pp.339-60.

ROGOFF,K. (1996). The Purchasing Power Parity puzzle. A reappraisal, Journal of Economic Literature, 34,pp. 647-68.

TAYLOR,M. L.SARNO (1998), The behaviour of real exchange rates during the post BW period, forthcoming Journal of International Economics. 
